\title{
Die Spannung steigt
}

Liebe Leserin, lieber Leser,

die Elektrifizierung des Antriebs zählt ohne jeden Zweifel zu den wichtigsten und intensiv diskutierten Themen unserer Branche. Es gilt als sicher, dass sich die Meisten künftig in Fahrzeugen von A nach $B$ bewegen werden, die in irgendeiner Form elektrifiziert sind. Einen nennenswerten Anteil daran werden sicher auch Mildhybride mit ihrem 48-V-Bordnetz stellen. Zwar ist diese Bordnetzspannung Stand heute noch überwiegend im Premiumsegment zu finden. Es zeichnet sich jedoch jetzt schon ab, dass es in sehr naher Zukunft auch zahlreiche Fahrzeuge in den unteren Segmenten mit einem 48-V-Bordnetz geben wird. Einen Vorgeschmack darauf bot schon der kürzlich zu Ende gegangene Genfer Autosalon. Am Ufer des Lac Léman präsentierten mehrere OEMs neue Modelle und Konzeptfahrzeuge, die mit diesem Bordnetz ausgestattet sind. Zwar betrachten noch längst nicht alle Hersteller $48 \mathrm{~V}$ als gesetzt, dennoch gibt es nicht wenige Fachleute, die darin das künftige Standardbordnetz sehen. $\mathrm{Ob}$ das weltweit gilt oder vornehmlich auf Europa beschränkt bleibt, wird die Zukunft allerdings noch zeigen müssen.

Für den Schwenk auf das neue Bordnetz gibt es viele gute Gründe. Mit seiner viermal höheren Spannung eröffnet sich eine Vielzahl an technischen Möglichkeiten, die sich mit den herkömmlichen $12 \mathrm{~V}$ nicht abdecken lassen. Die Bandbreite ist immens: Sie reicht von Komfortanwendungen über sicherheitsrelevante Lösungen bis hin zu erhöhter Performance durch elektrische Aufladung. Das alles geht einher mit einer deutlichen Kraftstoffeinsparung. Die 48-V-Systeme zeichnen sich aber nicht nur durch eine höhere Leistung und geringere Emissionen aus, sondern beides lässt sich obendrein zu deutlich niedrigeren Kosten erreichen als bei Vollhybriden. Die Mildhybride gelten als erschwinglicher, da hier unter anderem die schärferen Sicherheitsanforderungen der Hochvolttechnik nicht erfüllt werden müssen.

Es kann daher niemanden verwundern, dass viele OEMs und Zulieferer das Thema mittlerweile intensiv bearbeiten. Insofern lag es auch für unsere Redaktion nahe, nach der Erstausgabe im vergangenem Jahr, erneut ein ATZextra zu konzipieren, das sich dem Thema aus vielen Perspektiven nähert. Zulieferer, Entwicklungsdienstleister, OEMs und Forscher kommen in dieser Ausgabe zu Wort und beschreiben, wie sie die Chancen und Herausforderungen durch die neue Bordnetzspannung meistern wollen. Im Namen der gesamten Redaktion wünsche ich Ihnen eine angenehme und interessante Lektüre.

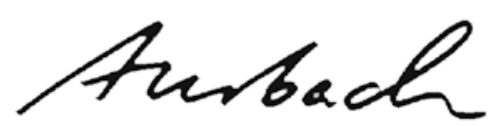

Benjamin Auerbach,

Editorial Manager Corporate Solutions

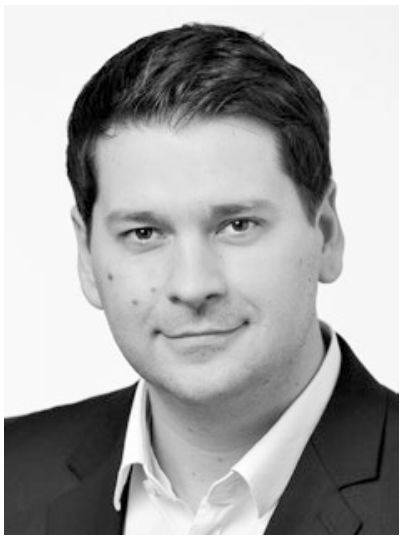

Beginnt in der Entwicklung.

Die Zukunft fährt elektrisch. Geringe Reichweite und lange Ladedauer bremsen jedoch aus. Mit energieeffizienten Batteriemanagementsystemen schalten wir Antriebe auf grün und möchten Menschen für saubere Mobilität begeistern. Von der Entwicklung Ihrer spezifischen Betriebs-, Bordnetz- und Ladestrategie bis hin zum prediktiven Reichweitenmanagement sorgen unsere Experten für freie Fahrt. Weil wir an Technologien arbeiten, die uns alle voran bringen.

ITK Engineering GmbH - Ihr Partner für saubere System- und Softwarelösungen.

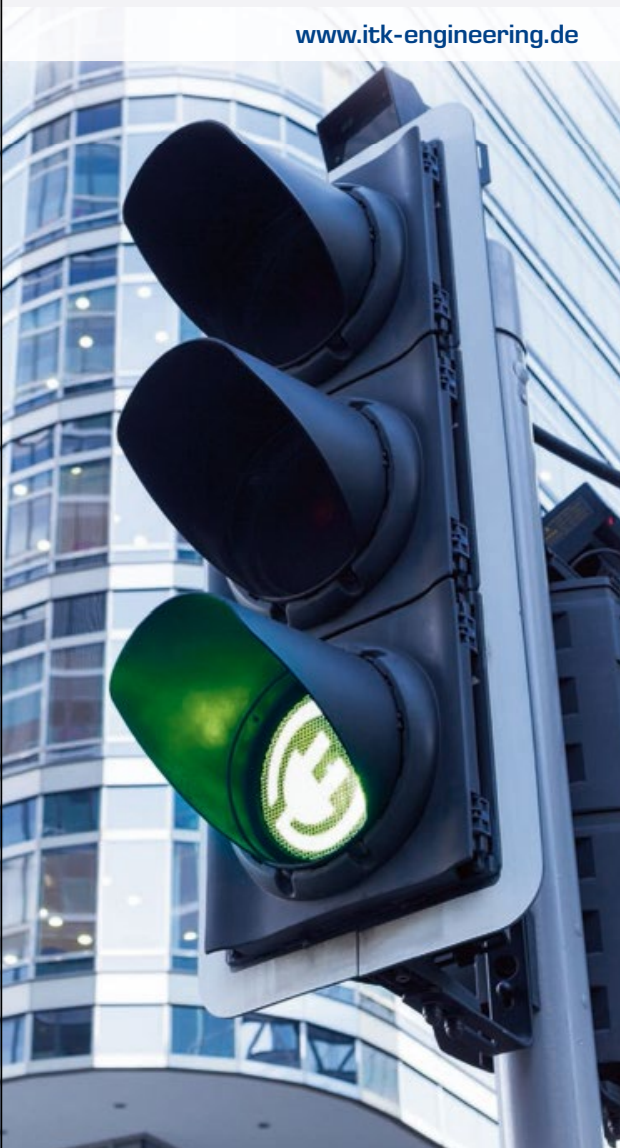

